Filol. Linguíst. Port., São Paulo, v. 16, n. spe, p. 233-259, dez. 2014 http://dx.doi.org/10.11606/issn.2176-9419.v16ispep233-259

\title{
Sentenças VOS em português europeu: movimento-p e estrutura entoacional
}

\author{
VOS sentences in European Portuguese: p-movement and \\ intonational structure
}

\author{
Flaviane Romani Fernandes-Svartman * \\ Universidade de São Paulo, São Paulo, São Paulo, Brasil
}

\begin{abstract}
Resumo: Este trabalho visa à análise da estrutura sintática e da estrutura entoacional associadas às sentenças VOS (sentenças na ordem verbo-objeto-sujeito) em português europeu (doravante, PE), com a hipótese de que a prosódia, refletida na estrutura entoacional, pode codificar a estrutura sintática associada às sentenças SVO neutras e a estrutura sintática associada às sentenças VOS de PE de maneiras distintas. Tal hipótese se baseia nos resultados experimentais apresentados em Frota (1994), os quais revelam que o contorno entoacional associado a estruturas sintáticas especiais em PE é afetado localmente (ou até globalmente) em relação ao contorno neutro. Para a investigação da referida hipótese, são analisadas, comparativamente, a estrutura sintática e a estrutura entoacional associada às sentenças SVO neutras e às sentenças VOS do PE. $\mathrm{Na}$ análise da estrutura sintática do último tipo de sentença, são trazidos argumentos, de cunho sintático e prosódico, em favor da derivação proposta por Fernandes (2007a), via movimento-p (Zubizarreta, 1998) do objeto. Já no que concerne à análise da estrutura entoacional das sentenças VOS de PE, com base nos resultados de Fernandes (2007a), é confirmada a hipótese inicial deste trabalho, na medida em que a estrutura entoacional associada às sentenças VOS de PE se revela distinta da estrutura entoacional associada às sentenças SVO neutras da mesma variedade de português.
\end{abstract}

\footnotetext{
* Professora do Departamento de Letras Clássicas e Vernáculas da Faculdade de Filosofia, Letras e Ciências Humanas da Universidade de São Paulo - USP, São Paulo, São Paulo, Brasil; flavianesvartman@usp.br.
} 
Diferentemente da estrutura entoacional das sentenças SVO neutras, a estrutura entoacional das sentenças VOS de PE apresenta mais acentos tonais e também um acento tonal específico, $\mathrm{L}^{*} \mathrm{H}$, associado ao objeto movido da margem direita da sentença, conforme a derivação sintática proposta no presente trabalho.

Palavras-chave: Português europeu. Sentenças VOS. Movimento prosódico. Entoação.

Abstract: This paper aims to analyze the syntactic and intonational structures associated with VOS sentences (sentences in verb-object-subject order) in European Portuguese (henceforth EP), with the hypothesis that prosody (reflected in intonational structure) can encode the syntactic structure associated with EP neutral sentences (sentences SVO - in subject-verb-object order) and the syntactic structure associated with EP VOS sentences in different ways. This hypothesis is based on the experimental results presented in Frota (1994), which reveal that the intonational contour associated with special syntactic structures of EP is affected locally (or even whole) in relation to the neutral contour. For the investigation of that hypothesis, the intonational and syntactic structures associated with EP SVO neutral sentences and with EP VOS sentences are comparatively analyzed. For the syntactic analysis of the latter type of sentences, syntactic and prosodic arguments are brought in favor of the derivation proposed by Fernandes (2007), by p-movement (Zubizarreta, 1998) of the object. Regarding the analysis of the intonational structure of EP VOS sentences, based on the results of Fernandes (2007), the initial hypothesis of this study is confirmed, since that the intonational structure associated with EP VOS sentences is different from the intonational structure associated with SVO neutral sentences of the same variety of Portuguese. Unlike the intonational structure of SVO neutral sentences, in the intonational structure of EP VOS sentences there are more pitch accents and also a specific pitch accent $\left(\mathrm{L}^{*}+\mathrm{H}\right)$ associated with the object moved from the right edge of the sentence, according to the syntactic derivation proposed in this paper.

Keywords: European Portuguese. VOS sentences. Prosodic movement. Intonation. 


\section{INTRODUÇÃO'}

O presente trabalho visa à análise da estrutura sintática e da estrutura entoacional associada às sentenças VOS (sentenças na ordem verbo-objeto-sujeito) em português europeu (doravante, PE). Apresentamos aqui uma análise expandida em relação à análise encontrada em Fernandes (2007a), no que tange particularmente à apresentação de argumentos na defesa da derivação das sentenças VOS de PE, via movimento-p (Prosodic Movement-p-movement "Movimento Prosódico - movimento-p" - Zubizarreta, 1998) do objeto.

De acordo com Âmbar (1992, 1999) e Costa (1996, 1998, 2004), as sentenças VOS em PE são utilizadas para expressar foco informacional do sujeito. ${ }^{2}$ Esse tipo de foco carrega informaçáo nova, mas não contrastiva, como apresentado em (1):

[Contexto: Tu sabes quem comeu o bolo. Eu ouvi dizer que alguém comeu o bolo, mas não percebi exactamente quem comeu o bolo. Então, pergunto-te: Quem comeu o bolo?]

\section{(1) Comeu o bolo o Paulo.}

Em (1), o sujeito focalizado, "o Paulo", aparece na última posição e carrega a proeminência principal da sentença.

Por outro lado, o foco contrastivo do sujeito em PE é expresso por sentenças $\mathbf{S V O}$ nas quais o sujeito $(\mathbf{S})$ ocupa a posiçáo inicial da sentença e carrega proeminência de foco prosódico, como pode ser visto no exemplo em (2):

[Contexto: Tu viste o Paulo a comer o bolo. Ouvi dizer que a Maria comeu o bolo, mas não tenho certeza disso. Então, pergunto-te: Comeu a Maria o bolo?]

(2) (Náo) O Paulo comeu o bolo.

1 Uma versão preliminar deste trabalho, fruto do desenvolvimento da pesquisa de Doutorado "Ordem e preenchimento em português: sintaxe e prosódia" (projeto financiado pela Fundação de Amparo à Pesquisa do Estado de São Paulo, processo FAPESP DD 03/13938-5, e, parcialmente, pela Coordenação de Aperfeiçoamento de Pessoal de Nível Superior, processo CAPES BEX 0183/05-9), orientada pela Profa. Charlotte M. C. Galves - Fernandes (2007a), foi apresentada, sob a forma de comunicação, no Workshop on "Interfaces", realizado no Instituto de Estudos da Linguagem da Universidade Estadual de Campinas, em 05 de junho de 2008.

2 Sobre outras formas de expressão de foco informacional do sujeito em PE, ver Âmbar (1999) e Fernandes (2007a).

Fernandes-Svartman FR. Sentenças VOS em português europeu: movimento-p e estrutura entoacional 
Quanto à estrutura entoacional associada às sentenças VOS em línguas como o PE e como o italiano, afirma-se, intuitivamente, que a elas está associada a mesma prosódia associada às sentenças SVO neutras (conferir Costa, 2004 para o PE e Belletti, 1999 para o italiano).

Nossa hipótese é a de que a prosódia, refletida na estrutura entoacional, pode codificar a estrutura sintática associada às sentenças SVO neutras e a estrutura sintática associada às sentenças VOS de PE de maneiras distintas. Essa hipótese se baseia nos resultados experimentais apresentados em Frota (1994), os quais revelam que o contorno entoacional associado a estruturas sintáticas especiais em PE é afetado localmente (ou até globalmente) em relação ao contorno neutro. ${ }^{3}$ Para a investigação de nossa hipótese, analisaremos comparativamente a estrutura sintática e a estrutura entoacional associada às sentenças neutras e às sentenças VOS do PE.

Defenderemos que a derivação sintática das sentenças VOS em PE se dá por movimento-p, à semelhança do que propóe Zubizarreta para o espanhol, e mostraremos que a evidência para tal proposta se encontra não só no comportamento sintático desse tipo de sentenças do PE, como no comportamento prosódico apresentado por elas. ${ }^{4}$

Este trabalho se encontra organizado nas próximas quatro seções. Na seção "Sentenças neutras do PE": (i) apresentamos a derivação sintática das sentenças SVO neutras dessa variedade de português, com base nos trabalhos de Duarte (1987, 1996), Âmbar (1992), Martins (1994) e Costa (1996, 1998, 2004); e (ii) descrevemos as características entoacionais associadas a esse tipo de sentença, conforme descrito em trabalhos anteriores (Frota, 1997, 2000, 2002a, b, 2003; Vigário, 1998; Fernandes, 2007a; Fernandes-Svartman, 2007b). Já na seção "Sentenças VOS do PE", apresentamos nossa proposta de derivação sintática, através do movimento-p, para as sentenças VOS do PE, bem como identificamos as características entoacionais associadas a essas sentenças, com base nos resultados de Fernandes (2007a). Por fim, na quarta e última seção, apresentamos nossas consideraçóes finais.

3 "Estruturas sintáticas especiais" significam aqui estruturas sintáticas diferentes das estruturas sintáticas associadas comumente às sentenças neutras (sobre a estrutura sintática associada às sentenças neutras de PE, cf. seção 2.1 deste trabalho).

4 Para a derivação sintática das sentenças VOS do PE através de movimento-p, conferir também Kato (1999).

Fernandes-Svartman FR. Sentenças VOS em português europeu: movimento-p e estrutura entoacional 


\section{SENTENÇAS NEUTRAS DO PE}

\subsection{Derivação sintática das sentenças SVO neutras do PE: a posição do sujeito}

Antes de apresentarmos a análise da estrutura sintática associada às sentenças neutras de PE, faz-se necessário definir o que entendemos por sentenças neutras neste trabalho e como elas são expressas em PE.

Assumimos que sentenças neutras são aquelas que apresentam uma ordem neutra, isto é, sentenças que apresentam uma ordem não marcada, nas quais não se encontram condições específicas (sintáticas, semânticas, prosódicas ou pragmáticas) associadas a elas. Atentemo-nos aos exemplos abaixo, extraídos de Âmbar (1992).

(3) a. A Joana comeu a sopa. (SVO)

b. A Joana, a sopa, comeu. (SOV)

c. Ontem comeu a Joana a sopa. (VSO)

d. A sopa, a Joana comeu. (OSV)

e. A sopa, comeu a Joana. (OVS)

f. Comeu a sopa, a Joana. (VOS)

A sentença SVO em (3a) é a única em que não há condições específicas associadas a ela. A gramaticalidade das outras sentenças depende de condiçóes específicas. Na sentença SOV em (3b), o objeto aparece entre vírgulas; na sentença VSO em (3c), há um advérbio no início da sentença; na sentença OSV em (3d), há uma vírgula depois do objeto e o sujeito porta proeminência de foco prosódico; na sentença OVS em (3e), há uma vírgula depois do objeto; e na sentença VOS em (3f), há uma vírgula antes do sujeito que porta proeminência de foco prosódico. Dado o exposto, conclui-se que sentenças neutras em PE são expressas pela ordem SVO.

Quanto à derivação sintática das sentenças SVO neutras de PE, assumimos a representada em (3a').

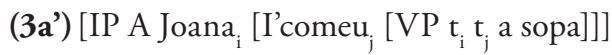

$\mathrm{Na}$ literatura sintática sobre a derivação sintática das sentenças SVO neutras de $\mathrm{PE}$, não há grandes polêmicas quanto às posiçóes ocupadas pelo verbo e 
pelo objeto..$^{5}$ As posiçóes tradicionalmente aceitas para esses dois elementos são as que assumimos aqui, ou seja, o verbo ocupa a posição de núcleo de Infle o objeto, a sua posição de base em VP (Costa, 1998, 2004).

Por outro lado, quanto à posição do sujeito pré-verbal desse mesmo tipo de sentença em PE, encontramos certa controvérsia na literatura relevante sobre esse tópico. Essencialmente há duas propostas de análise para a posição sintática ocupada pelo sujeito pré-verbal das sentenças SVO neutras do PE: (1) posição-A' de deslocamento à esquerda (adjunção a IP), como defendido por Barbosa (1995, 2000) e, para casos específicos, como os de sujeitos pré-verbais em resposta a interrogativas múltiplas, como defendido por Costa (2001); e (2) posição-A de especificador de IP, como defendido por Âmbar (1992), Duarte (1987, 1996), Martins (1994), Costa (1996, 1998, 2004), entre outros. ${ }^{6}$

Neste trabalho, defendemos a segunda proposta, ou seja, assumimos, juntamente com Âmbar (1992), Duarte (1987, 1996), Martins (1994) e Costa (1996, 1998, 2004), que o sujeito pré-verbal das sentenças neutras do PE se encontra na posição argumental de especificador de IP.?

Baseado em autores como Âmbar (1992), Duarte (1987, 1996) e Martins (1994), Costa (1996, 1998, 2004) defende que o sujeito pré-verbal das sentenças neutras de PE ocupa a posição de especificador de IP, ou seja, uma posição-A, contrariando a afirmação de Barbosa $(1995,2000)$, conforme a qual, os sujeitos em posição pré-verbal ocupam uma posição-A' em PE. A afirmação de Costa se baseia em argumentos como os que apresentamos abaixo (Costa, 1998, 2004):

(i) Sintagmas quantificacionais (QPs) negativos desacentuados:

Belletti (1990) afirma que em línguas como o italiano, nas quais o sujeito pré-verbal é deslocado à esquerda, um QP negativo pode ocorrer apenas antes de um advérbio sentencial, se o QP negativo porta uma proeminência de foco prosódico, como exemplificado em (4b). Segundo a análise de Belletti, um QP negativo acentuado é A'-movido. A impossibilidade de não-adjacência entre QPs

5 Para uma discussão mais aprofundada sobre a posição do verbo em português, ver Costa e Galves (2002).

6 Para maiores detalhes sobre a proposta (1) de análise da posição sintática ocupada pelo sujeito pré-verbal de PE, remetemos o leitor aos trabalhos de Barbosa $(1995,2000)$ e Costa (2001).

7 Nós não consideramos aqui a hipótese do IP estendido. Sobre esse tópico, conferir Pollock (1989); Belletti (1990); Iatridou (1990); entre outros. Já sobre esse tópico para o português, conferir Galves (1993, 2001); Figueiredo Silva (1996); Kato (1999, 2000); Costa e Galves (2002); Tavares Silva (2004); entre outros.

Fernandes-Svartman FR. Sentenças VOS em português europeu: movimento-p e estrutura entoacional 
negativos desacentuados e um verbo flexionado é explicada em termos da impossibilidade de deslocamento à esquerda de QPs negativos.

$\mathrm{O}$ exemplo em (4a) mostra que, em PE, diferentemente do italiano, o QP negativo desacentuado pode ocorrer antes de um advérbio sentencial. Tal fato indica que o QP pré-verbal negativo não é necessariamente deslocado à esquerda, como é proposto em Barbosa $(1995,2000)$. QPs negativos em PE ocupam a posiçáo de especificador de IP, que não é inerentemente associada a propriedades de tópico, podendo ser desacentuados, desde que não ocupem uma posição A'.

(4) a. Ninguém provavelmente leu esse livro.

b. Nessuno/*Nessuno probabilmente ha sbagliato.

"Ninguém provavelmente errou."

(ii) Ausência de efeitos de minimalidade

Atentemo-nos aos exemplos em (5):

(5) a. Perguntei que livros o Paulo leu.

b. *Perguntei que livros, à Maria, lhe deram.

A agramaticalidade da sentença apresentada em (5b) pode ser explicada por efeitos de minimalidade. O movimento de "que livros" (que é um movimento $\mathrm{A}^{\prime}$ ) para a esquerda do constituinte deslocado à esquerda "à Maria" se configura em um problema de minimalidade. Se o sujeito ocupa a posição de especificador de IP nas sentenças do PE, como a apresentada em (5a), espera-se que tal elemento não crie um problema de minimalidade, uma vez que ocupa uma posição-A.

(iii) Múltiplos elementos deslocados à esquerda

Quando dois complementos do verbo são prepostos (deslocados à esquerda), a ordem relativa desses elementos não é rígida em PE, como exemplificado em (6a). Se o sujeito pré-verbal é também deslocado à esquerda (por exemplo, se ele é adjungido a IP, como na análise de Barbosa), espera-se que a ordem entre um complemento preposto (deslocado à esquerda) e o sujeito não seja rígida. Entretanto, nota-se o contraste entre (6b) e (6c):

(6) a. Sobre sintaxe, aos alunos, o Rui falou.

b. ?? O Paulo, esse bolo, comeu-o.

c. Esse bolo, o Paulo comeu-o. 
Levando em conta os argumentos extraídos de Costa (1998, 2004), é possível assumirmos, juntamente com esse autor, que o sujeito pré-verbal das sentenças SVO neutras de PE ocupa uma posição-A, mais especificamente, a posição de especificador de IP.

\subsection{A estrutura entoacional associada às sentenças $\mathrm{SVO}$ neutras de $\mathrm{PE}^{8}$}

A estrutura entoacional associada às sentenças SVO neutras de PE é essencialmente caracterizada por eventos tonais associados apenas às fronteiras inicial e final do sintagma entoacional (I - do inglês intonational phrase) no qual esse tipo de sentença é mapeado. ${ }^{9}$ De acordo com os resultados obtidos pelos trabalhos de Frota (1997, 2000, 2002a, b, 2003), Vigário (1998), Fernandes (2007a) e Fernandes-Svartman (2007b), entre outros, sobre a estrutura entoacional das sentenças neutras do $\mathrm{PE}$, há eventos tonais associados à primeira e à última palavras prosódicas (PWd, do ingles prosodic word) de I desse tipo de sentença. ${ }^{10}$

A representação em $\left(7^{\prime}\right)$ e a figura respectiva (Figura 1) da sentença SVO de PE em (7), produzida em contexto neutro por um falante nativo dessa variedade de português, ilustram o exposto.

(7) As miúdas belas lavaram as luvas.

(7') $\left[\left[\left(\right.\right.\right.$ as miúdas)PWd(Belas)PWd] $\mathrm{PPh}\left[(\right.$ lavaram)PWd]PPh[(as Luvas)PWd]PPh $] \mathrm{I}^{11}$

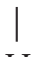

$\mathrm{H}$

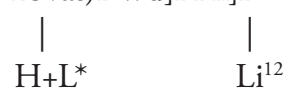

8 Para a descrição das características entoacionais das sentenças neutras de PE, valer-nos-emos dos trabalhos mais recentes desenvolvidos sobre a entoação do PE no quadro teórico da Fonologia Etoacional (Pierrehumbert, 1980; Beckman e Pierrehumbert, 1986; Pierrehumbert e Beckman,1988; Ladd, 1996, 2008). Especificamente, valer-nos-emos dos resultados obtidos por Frota $(1997,2000$, 2002a,b, 2003); Vigário (1998); Frota e Vigário (2000); Fernandes (2007a) e Fernandes-Svartman (2007b). Os exemplos apresentados no decorrer desta seção são extraídos dos trabalhos de Fernandes (2007a) e Fernandes-Svartman (2007b).

9 Sobre o sintagma entoacional em PE, ver Frota (2000).

10 Sobre a palavra prosódica em PE, ver Vigário (2003).

11 As sílabas em letras maiúsculas representam sílabas acentuadas; as palavras prosódicas (PWd) aparecem delimitadas por parênteses; os sintagmas fonológicos ( $\mathrm{PPh}$ - do inglês phonological phrase), por colchetes; e o sintagma entoacional (I) também aparece delimitado por colchetes. Sobre a formação de PPhs em PE, ver Frota (2000).

12 Neste trabalho, o tom de fronteira L\% (notação de Pierrehumbert) é transcrito como Li, seguindo a notação dos trabalhos de Frota (1997, 2000, 2002a, b, 2003), Fernandes (2007a) e Fernandes-Svartman (2007b) para o português europeu.

Fernandes-Svartman FR. Sentenças VOS em português europeu: movimento-p e estrutura entoacional 


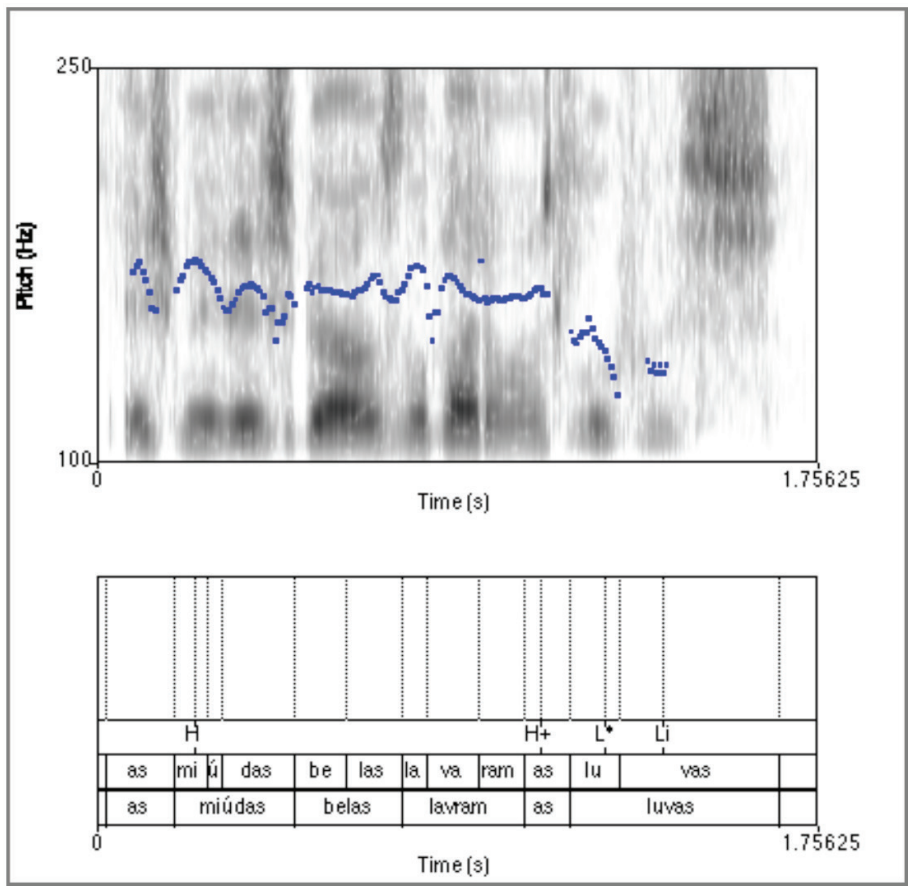

Figura 1. Contorno de $\mathrm{F}_{0}$ da sentença "As miúdas belas lavaram as luvas", produzida em contexto neutro por um falante nativo de PE

Nota-se, através da observação da representação em (7') e da respectiva Figura 1, eventos tonais associados apenas à palavra prosódica inicial, "as miúdas" (evento tonal $\mathrm{H}$ associado à sílaba "mi" da palavra "miúdas"), e à palavra prosódica final, "as luvas" (acento tonal $\mathrm{H}+\mathrm{L}^{*}$ associado à sílaba tônica "lu" e tom de fronteira Li associado à postônica final "vas" da palavra "luvas"), do sintagma entoacional "As miúdas belas lavaram as luvas".

\section{SENTENÇAS VOS DO PE}

\subsection{Derivaçáo sintática das sentenças VOS do PE}

Como já referido anteriormente, as sentenças na ordem VOS são usadas em PE para se expressar foco informacional do sujeito. Neste trabalho, assumimos com Kato (1999) que esse tipo de sentença em PE é derivado sintaticamente por movimento-p (Zubizarreta, 1998), e não por scrambling, como propóe Costa $(1998,2004)$. Entretanto, nossa proposta diverge da de Kato quanto ao elemento 
movido por movimento-p na derivação das sentenças VOS. Enquanto essa pesquisadora propóe que as sentenças VOS do PE são derivadas por movimento-p de $\mathrm{VO}$, como proposto por Zubizarreta para o italiano, propomos que o elemento movido por movimento-p na derivação das mesmas sentenças em PE é apenas o objeto $(\mathrm{O})$, como proposto por Zubizarreta para o espanhol. Na defesa de nossa derivação sintática, apresentaremos alguns dos argumentos extraídos de Costa (2004), os quais sustentam o movimento de $\mathrm{O}$, e não de $\mathrm{VO}$, na derivação das sentenças VOS do PE, mas também apresentaremos argumentos que sustentam o movimento de $\mathrm{O}$ por movimento-p, e não por scrambling, como propóe Costa.

\subsubsection{Derivaçáo das sentenças VOS do PE via movimento-p}

De acordo com Zubizarreta, o movimento-p não é motivado pela checagem de traços sintáticos, mas ocorre quando dois nós "a" e "b" possuem propriedades contraditórias conforme representado em (8). "a" e "b" possuem propriedades contraditórias se e somente se:

(i) “a" e "b" são irmãos métricos;

(ii) "a" porta proeminência de foco prosódico (atribuído pela regra de proeminência de foco - Focus Prominence Rule $(F P R))^{13}$ e "b" porta a proeminência principal da sentença (atribuída pela regra nuclear de acento - Nuclear Stress Rule (NSR)), ou vice-versa. ${ }^{14}$

$\ldots\left[{ }_{d}\left[\mathrm{ph}^{*}\right] \ldots\left[{ }_{b} \mathrm{ph}^{*}\right]\right]$, where $\mathrm{a}$ and $\mathrm{b}$ are metrical sisters. - Zubizarreta $(1998, \mathrm{p} .139)$

Levando em consideração a definição do movimento-p proposto por $\mathrm{Zu}$ bizarreta, defendemos aqui que a derivação das sentenças VOS de PE ocorre como representado em (8b), por movimento-p do objeto:

13 A formulação de FPR, proposta por Zubizarreta, é a seguinte: Given two sister nodes Ci (marked $[+\mathrm{F}])$ and $\mathrm{Cj}$ (marked [-F]), $\mathrm{Ci}$ is more prominent than $\mathrm{Cj}$.

14 Pela NSR, proposta por Chomsky e Halle (1968), o acento principal de uma sentença é assinalado automaticamente por regras fonológicas regulares, independentemente de consideraçóes discursivas. Em línguas de recursividade sintática à direita, como o inglês: the Nuclear Stress Rule assigns primary stress to the rightmost primary-stressed vowel, weakening all others, and giving the stress contour (Chomsky e Halle, 1968, p. 22). Para os autores, em uma sentença do inglês como John's blackboard eraser was stolen ("O apagador de lousa do João foi roubado"): há primeiramente a aplicação de regras que atribuem acentos principais aos itens lexicais no interior de cada sintagma a que pertencem e, por fim, no nível da sentença, a NSR assinala o acento principal à palavra stolen (item lexical mais à direita na sentença), enfraquecendo os demais acentos atribuídos aos outros itens lexicais.

Fernandes-Svartman FR. Sentenças VOS em português europeu: movimento-p e estrutura entoacional 
(8) a. Levaram as malas as governadoras.

b. [IP ... levaramj [VP as malasl [VP as governadoras tj $\mathrm{t}$ l]]]

Podemos considerar as sentenças VOS de PE como casos de movimento-p (como a apresentada em (8a), com a respectiva derivação sintática representada em (8b)), porque tais sentenças apresentam todas as propriedades do movimento -p listadas por Zubizarreta:

(i) Sentenças VOS são possíveis em PE apenas em contexto de foco informacional do sujeito (quando há interação entre a proeminência de foco prosódico e a proeminência principal da sentença) - cf. Fernandes (2007a):

(9) Contexto: Tu sabes que as governadoras levaram as malas quando foram viajar. Eu ouvi dizer que alguém levou as malas, mas não percebi exactamente quem, então, pergunto-te: Quem levou as malas?

Resposta de um falantes nativo de PE:

Levaram as malas as governadoras.

(ii) O movimento do objeto não é motivado por checagem de traço sintático:

a. É o sujeito o elemento que porta o traço de foco $(+\mathrm{F})$ que deve ser checado, náo o objeto;

b. O objeto pode checar seu traço de Caso através da operação Agree (Chomsky, 2000, 2001, 2004), logo, não é necessário o movimento de adjunçấo a VP do objeto para checagem de seu traço de Caso;

c. O movimento do objeto é local e ocorre no contexto em que o sujeito e o objeto possuem propriedades prosódicas contraditórias, como demonstrado em (8b').

(8b') $\quad\left[\mathrm{IP}\right.$... levaram $_{\mathrm{j}}\left[\mathrm{VP}\right.$ as governadoras $\mathrm{t}_{\mathrm{j}}$ as malas $\left.]\right]$

仓

FPR

NSR

Passemos agora à apresentação de argumentos que sustentam nossa derivação sintática para as sentenças VOS em PE, como exposto em (8b). 


\subsubsection{Sentenças VOS do PE: movimento de O cruzando S em SpecVP ou movimento de VO?}

Uma análise alternativa para a derivação da ordem dos elementos nas sentenças VOS das línguas românicas é através do movimento de VO, também chamado de Remnant Movement ("Movimento Remanescente"). Conforme esse tipo de análise, há movimento do sujeito para SpecIP ou para alguma projeção funcional na periferia esquerda e movimento do constituinte remanescente, VP, contendo o traço do sujeito, para uma posição mais alta que aquela para qual o sujeito foi movido (conferir, para o italiano, Kayne, 1998; Kayne e Pollock, 1998; Zubizarreta, 1998; para o espanhol, Bok-Benema, 1998; e, para o PE, Âmbar e Pollock, 1998; Kato, 1999).

Entretanto, há argumentos empíricos, apresentados por Costa (2004), que desfavorecem uma análise por movimento de VO para a derivação das sentenças VOS de PE. Costa mostra que os problemas encontrados para uma análise por movimento de $\mathrm{VO}$ não são encontrados em uma análise de movimento de O na derivação da ordem VOS. Abaixo, reproduzimos alguns dos argumentos apresentados por Costa, os quais permitem sustentar a análise de VOS por movimento de $\mathrm{O}$, e não de $\mathrm{VO}$, em $\mathrm{PE}$ :

\section{A. Mobilidade de VP}

Segundo uma análise por movimento de VO, em uma sentença como a apresentada em (10a), o constituinte VP "leu o livro" é movido para a esquerda do sujeito. A clivagem é uma evidência independente para esse movimento, uma vez que o VP contendo o verbo e o objeto pode ser clivado, como mostra (10b).

(10) a. Leu o livro o Pedro.

b. Foi ler o livro o que o Pedro fez.

Entretanto, se há forma verbal complexa (como em (11)), a evidência para o movimento de VP náo é encontrada. Nesse caso, o constituinte VP não pode aparecer clivado à esquerda do sujeito, como revela a agramaticalidade de (11b). Através de uma análise por movimento de $\mathrm{O}$, tal problema não é encontrado, dado que o objeto pode ser movido à esquerda do sujeito, independentemente da complexidade da forma verbal, como pode ser visto em (11c).

(11) a. Tinha lido o livro o Paulo.

b. *Era ter lido o livro o que o Paulo tinha feito. 
c. Era o livro o que o Paulo tinha lido.

B. Distribuição dos advérbios monossilábicos

Advérbios monossilábicos como "mal" e "bem" em PE têm uma distribuição muito restrita. Em sentenças VOS, eles ocorrem apenas em duas posiçóes: ou entre o objeto e o sujeito, ou entre o verbo e o objeto:

(12) a. Leu os livros mal o Paulo.

b. Leu mal aqueles livros o Paulo.

Uma análise de VOS por movimento de VO não oferece uma explicação natural para o porquê de só haver dois lugares possíveis para os advérbios monossilábicos nas sentenças VOS de PE. Por movimento de O há explicação para esse fato: o objeto é adjungido a VP e náo há ordem fixa para dois adjuntos de VP, Adv e $\mathrm{O}$, assim, podem ser encontradas tanto a ordem VAdvOS, como a ordem VOAdvS.

C. Clíticos: ênclise vs. Próclise

Outro argumento para a defesa da derivação das sentenças VOS de PE por movimento de O e não de VO se encontra no fato de DPs sujeitos quantificados em SpecIP desencadearem próclise, e não ênclise (Duarte e Matos, 2000; entre outros).

$\mathrm{Na}$ análise das sentenças VOS de PE por movimento de VO, o sujeito está em SpecIP e o constituinte contendo VO (VP) é movido para a esquerda do sujeito na posição de especificador de IP.

Todavia, se são consideradas as sentenças VOS de PE com DPs sujeitos quantificados, nota-se um problema. Se o VP é movido para a esquerda do DP sujeito quantificado em SpecIP, deveria ser encontrada próclise. Porém, não é isso o que acontece, como mostra a agramaticalidade da sentença em (13b). Através de uma análise de VOS por movimento de $\mathrm{O}$, o mesmo problema não surge, posto que o sujeito quantificado está em SpecVP e, portanto, não há o desencadeamento de próclise.

(13) a. Ontem deram-no a Maria todos os meninos.

b. * Ontem oi deram à Mariai todos os meninos ti.

Com relação à posição ocupada pelo sujeito nas sentenças VOS de PE, é possível defender a posição de especificador de VP para esse elemento, baseandonos nos seguintes argumentos também apresentados por Costa $(1998,2004)$ : 


\section{Distribuição dos advérbios baixos}

Aplicando o teste de distribuição de advérbios monossilábicos baixos (sempre adjungidos a VP, conforme a proposta de Costa, 1998), como "bem", temos o seguinte resultado para a posição do advérbio "bem" nas sentenças VOS do PE:

(14) a. Comeu bem a sopa o Paulo.

b. Comeu a sopa bem o Paulo.

c. ${ }^{*}$ Comeu a sopa o Paulo bem.

Os exemplos em (14) mostram que, independentemente da posição ocupada pelo objeto nas sentenças VOS (interna a VP, (14a), ou externa a esse constituinte, (14b) e (14c)), o sujeito é sempre interno a VP, aparecendo obrigatoriamente à direita do advérbio baixo "bem", adjungido a VP.

\section{Efeitos de ligação}

Como é bem sabido, movimento-A permite ligação, entretanto, não pode haver ligação com movimento-A'. O exemplo em (15b) mostra que em sentenças VOS identificadas, de fato, como instâncias de deslocamento à direita do sujeito, i. e., casos em que uma pergunta-eco pode intervir entre o objeto e o sujeito e há movimento-A, a ligação é possível. Entretanto, na sentença VOS em (15a), a ligação não é permitida. Isso porque o movimento-A' do objeto, cruzando o sujeito em SpecVP, não permite ligação.

(15) a. *Viu [objeto o Pauloi] [sujeito o seui irmão]

b. Viu [objeto o Pauloi], não viu?, [sujeito o seui irmão]

\section{Sujeitos definidos e indefinidos}

Sujeitos pós-verbais nas sentenças VOS do PE podem ser definidos ou indefinidos, como exemplificado respectivamente em (16a) e (16b). O fato de a definitude do sujeito náo afetar a aceitabilidade das sentenças VOS de PE atesta que a ordem VOS náo é necessariamente derivada em termos de deslocamento à direita do sujeito, uma vez que em casos verdadeiros de deslocamento à direita, como os apresentados em (16c) e (16d), sujeitos indefinidos são marginais, como revela (16d). 
(16) a. Comeu a sopa o Paulo.

b. Comeu a sopa um homem.

c. Comeu a sopa, não comeu?, o Paulo.

d. *Comeu a sopa, não comeu?, um homem qualquer.

Justificada a derivação sintática por nós assumida para as sentenças VOS do PE, no que tange especificamente ao movimento de $\mathrm{O}$, cruzando $\mathrm{S}$, que permanece em SpecVP, faz-se necessário ainda sustentar nossa proposta de ser o movimento do objeto um caso de movimento-p, nos moldes do que propóe $\mathrm{Zu}$ bizarreta (1998) para as sentenças VOS do espanhol, e não um caso de object-shift ou, como propóe Costa $(1998,2004)$ para o mesmo tipo de sentença do PE, um caso de scrambling.

\subsubsection{Movimento-p vs. Object-shift e Scrambling}

De acordo com Vikner (1994), as construçóes de scrambling são encontradas em línguas germânicas ocidentais, como o alemão e o holandês e, nesse tipo de construção, há movimento-A'. As construçóes de scrambling apresentam as seguintes propriedades, conforme esse autor: (a) não permitem ligação; (b) NPs e PPs podem ser movidos por scrambling; (c) efeito de novidade; e (d) licenciamento de ilhas parasíticas.

Já as construções object-shift, segundo Vikner, são construções encontradas em línguas escandinavas e derivadas através de movimento-A. Esse tipo de construção, para o mesmo autor, apresenta as seguintes propriedades: (a) permite ligação; (b) movimento apenas de NPs; e (c) não licenciamento de ilhas parasíticas.

Levando em conta as propriedades das construçóes de scrambling e $o b$ ject-shift, Costa (2004) afirma que as sentenças VOS do PE são derivadas via scrambling do objeto. Eis os argumentos apresentados por Costa como evidência dessa afirmação:

(a) Sentenças VOS em PE não permitem ligação, como revela a agramaticalidade das sentenças apresentadas em (17a) e (17b), o que indica ser o movimento do objeto do tipo movimento-A', e não movimento-A.

(17) a. ${ }^{*}$ Viu o seui pai cadai criança.

b. ${ }^{*}$ Viu cadai criança seui pai.

(b) Nas construções de scrambling em PE, é possível mover tanto NPs, quanto PPs (cf. (19bB)): 
(18) a. A: Como é que o Paulo fala francês?

B: O Paulo fala francês bem.

B': \#O Paulo fala bem francês.

b. A: Como é que o Paulo fala com estrangeiros?

B: O Paulo fala com estrangeiros bem.

B': \#O Paulo fala bem com estrangeiros.

(c) As construçóes de scrambling em PE apresentam efeito de novidade, como pode ser atestado pela observação dos exemplos em (18).

Embora as sentenças VOS do PE, na comparação entre construções de scrambling e object-shift, comportem-se como construções do primeiro tipo, na comparação entre construçóes de scrambling, object-shift e movimento-p, elas parecem se comportar mais como casos de movimento-p do que como casos de construçôes dos outros dois tipos. Isso porque as sentenças VOS do PE, além de apresentarem características que as diferenciam de construçóes object-shift, também estão sujeitas a uma restrição prosódica típica apenas de construçóes de movimento-p, que é a Restrição de Peso Relativo (Zubizarreta, 1998).

É possível afirmar que as sentenças VOS de PE, se consideradas como derivadas por movimento-p, apresentam características que as diferenciam das construçóes object-shift, na medida em que: (i) aparecem no mesmo contexto em que as construçôes de scrambling, ou seja, contexto de foco informacional, como pode ser visto em (9), portanto, apresentam efeito de novidade; e (ii) são casos de movimento A', como propomos na derivação em (8b), uma vez que sentenças como as apresentadas em (17), nas quais é mostrado que não há ligação (propriedade de movimento-A'), poderiam ser geradas por um tipo de derivação como o apresentado em (8b). No que diz respeito ao fato de construçóes object-shift permitirem apenas movimento de NPs, cabe observar que o movimento-p, assim como as construçóes de scrambling, permite tanto movimento de NPs como de PPs.

De acordo com Zubizarreta, o movimento-p ocorre não só na focalização informacional do sujeito em espanhol, como também na focalização de objetos e advérbios.

Assim, em resposta a (19), tem-se (20a), com o objeto direto portando foco informacional na margem direita da sentença, sendo agramatical a resposta em (20b), na qual o advérbio, mas não o objeto focalizado, ocupa aquela posição. No caso de (20a), conforme Zubizarreta, o objeto focalizado ocupa a margem direita da sentença, uma vez que o advérbio (no exemplo, um PP) é movido dessa 
posição por movimento-p, para que haja correspondência entre a proeminência assinalada pela NSR e a proeminência de foco assinalada pela FPR.

(19) a. ¿Qué cosa Ana escondió debajo de la cama?

"O que Ana escondeu debaixo da cama?"

(20) a. Ana escondió debajo de la cama la muñeca.

"Ana escondeu debaixo da cama a boneca."

b. *Ana escondió la muñeca debajo de la cama.

Por sua vez, no caso de focalização informacional do sujeito em espanhol, quando a ordem VOS é obtida, é o NP objeto que se move da margem direita da sentença, via movimento-p, conforme a mesma autora, para que o sujeito focalizado ocupe essa posição, como ilustrado pelo exemplo em (21b).

(21) a. ¿Quién te regaló la botella de vino?

"Quem te deu a garrafa de vinho?"

b. Me regaló la botella de vino María.

"*Me deu a garrafa de vinho Maria."

Portanto, atesta-se que tanto NPs quanto PPs podem ser movidos via movimento-p. Isso posto, uma sentença do PE, como a apresentada em (18bB), na qual o PP "com estrangeiros" é movido, também poderia ser derivada por movimento-p, dada a semelhança de contexto de ocorrência ao ser comparada, por exemplo, à sentença (20a) do espanhol, derivada via movimento-p do PP debajo de la cama.

Com relação à Restrição de Peso Relativo à que o movimento-p é sensível, eis a formulação de tal restrição, conforme Zubizarreta (1998, p. 137):

The Relative Weight Constraint

P-movement of constituent A across constituent B is degraded if A is 'metrically heavier' than $\mathrm{B}$.

Nas palavras de Zubizarreta (1998, p. 137), entenda-se por "metricamente mais pesado":

$A$ is 'metrically heavier' than $B$ if $A$ is branching and $B$ is not (where only metrically visible material counts for computing 'branchingness'), unless B has heavier pitch than A. 
Com base nos resultados empíricos obtidos por Fernandes (2006, 2007a), é possível afirmar que as sentenças VOS de PE (nas quais o objeto é o elemento movido, conforme os argumentos apresentados na seção 3.1.2 deste artigo) estão sujeitas à Restrição de Peso Relativo, conforme proposto por Zubizarreta.

Segundo Fernandes (2006, 2007a), objetos curtos (formados por até três sílabas, e.g., "o texto") e longos (compostos por mais de três sílabas, e.g., "os documentos") proporcionam um ligeiro aumento da escolha, pelos falantes nativos de PE, por sentenças VOS, ao invés de sentenças SVO, em contexto de focalização informacional do sujeito $(6,9 \%$ (19) de escolha, pelos falantes de PE, por sentenças VOS em 100\% (276) dos dados de objeto curto e 6,9\% (15) de escolha por sentenças VOS em 100\% (216) dos dados de objeto longo), se tomamos por comparaçáo a escolha, pelos falantes nativos da mesma variedade de português, por sentenças VOS compostas por objetos ramificados sintática e fonologicamente (compostos por duas palavras prosódicas e por dois sintagmas sintáticos, e.g., "os papéis velhos" [(os papéis)PWd]NP[(velhos)PWd]AP) e objetos ramificados apenas fonologicamente (compostos por duas palavras prosódicas e um único sintagma sintático, e.g., "o Joãozinho" [(o João)PWd(zinho)PWd]NP), no mesmo contexto já referido (respectivamente, 2,8\% (6) de escolha por sentenças VOS em $100 \%$ (216) dos dados de objetos ramificados sintática e fonologicamente e 4,6\% (10) de escolha por sentenças VOS em 100\% (216) dos dados de objetos ramificados apenas fonologicamente). Tais resultados indicam que é a ramificação, e não o número de sílabas, o fator determinante para o peso fonológico do objeto nas sentenças transitivas do PE. Ou seja, sentenças VOS são preteridas em PE, ainda que em contexto de focalizaçáo informacional do sujeito, quando o objeto é pesado, em termos de ramificação sintática e fonológica, o que indica que esse tipo de sentença do PE está, de fato, sujeito à Restrição de Peso Relativo à que é sensível o movimento-p.

Um argumento contrário à derivação das sentenças VOS de PE via movimento-p poderia ser o fato de as sentenças VOS apresentarem sensibilidade à definitude do objeto, de acordo com Costa (2004). Costa (2004) afirma intuitivamente que, se o objeto é indefinido, a aceitabilidade das sentenças é afetada, como revelam as diferenças de grau de aceitabilidade das sentenças em (22), extraídas do trabalho do referido autor.

(22) a. ?Viu um gato o Paulo.

b. *Viu um homem qualquer o Paulo.

c. ?? Leu algo o Paulo. 
A relação entre propriedades semânticas do objeto (como definitude) e grau de aceitabilidade das sentenças VOS não poderia ser explicada se considerado que o movimento-p é um movimento sensível a propriedades prosódicas, mas não semânticas, do elemento movido. Entretanto, esse argumento não invalida nossa proposta de derivação das sentenças VOS de PE, via movimento-p, uma vez que a existência da relação entre grau de definitude do objeto e grau de aceitabilidade das sentenças VOS não parece ser fato de comum consenso entre os falantes dessa variedade de português, conforme revelam dados empíricos.

Da aplicação de um teste a um grupo de falantes nativos de PE, obtivemos os seguintes resultados sobre a relação entre grau de definitude do objeto e grau de aceitabilidade das sentenças VOS em contexto de focalização informacional do sujeito: (i) em $100 \%$ (28) das sentenças VOS cujo objeto era composto por artigo indefinido + NP (ex.: "um livro"), 32\% (9) foi considerado muito pouco aceitáveis ou pouco aceitáveis pelos falantes de PE, 29\% (8) foi considerado razoavelmente aceitável e 39\% (11) foi considerado aceitável ou perfeitamente aceitável; (ii) $45 \%$ das sentenças VOS cujo objeto era definido (formado por artigo definido + NP - ex.: "a sopa") foram consideradas muito pouco aceitáveis ou pouco aceitáveis, $21 \%$ desse mesmo tipo de sentença foi considerado razoavelmente aceitável e $34 \%$ das sentenças foram consideradas aceitáveis ou perfeitamente aceitáveis; (iii) em 100\%(28) das sentenças VOS cujo objeto era composto por pronome indefinido (ex.: "algo"), 57\% (16) das sentenças foram consideradas muito pouco aceitáveis ou pouco aceitáveis, 32\% (9) desse mesmo tipo de sentença foi considerado razoavelmente aceitável e 11\% (3) das sentenças foram consideradas aceitáveis ou perfeitamente aceitáveis; e (iv) em 100\%(28) das sentenças VOS cujo objeto era formado por artigo indefinido + NP + "qualquer" (ex.: "uma jarra qualquer"), $61 \%$ (17) das sentenças foram consideradas muito pouco aceitáveis ou pouco aceitáveis, $14 \%$ (4) desse mesmo tipo de sentença foi considerado razoavelmente aceitável e 25\% (7) das sentenças foram consideradas aceitáveis ou perfeitamente aceitáveis. ${ }^{15}$

Esses resultados revelam não haver consenso entre os falantes de PE quanto à existência da relaçáo entre grau de definitude do objeto e grau de aceitabilidade das sentenças VOS, uma vez que, por exemplo, sentenças VOS, cujo objeto é formado por artigo indefinido + NP são consideradas, pelos falantes de PE, mais aceitáveis que sentenças VOS cujo objeto é definido (39\% das sentenças VOS do primeiro tipo foram consideradas aceitáveis ou perfeitamente aceitáveis,

15 Agradeço a Maria Luisa Zubizarreta pela sugestão de aplicação do teste sobre a relação entre grau de definitude do objeto e grau de aceitabilidade das sentenças VOS do PE a falantes nativos dessa mesma variedade de português.

Fernandes-Svartman FR. Sentenças VOS em português europeu: movimento-p e estrutura entoacional 
enquanto 34\% (19) de 100\% (56) das sentenças VOS do segundo tipo foram consideradas aceitáveis ou perfeitamente aceitáveis); por outro lado, sentenças VOS, cujo objeto é formado por artigo indefinido + NP + "qualquer" são consideradas mais aceitáveis que sentenças VOS cujo objeto é composto pelo pronome idefinido "algo" pelos falantes da já referida variedade de português $(25 \%$ das sentenças VOS do primeiro tipo foram consideradas aceitáveis ou perfeitamente aceitáveis, enquanto $11 \%$ das sentenças VOS do segundo tipo foram consideradas aceitáveis ou perfeitamente aceitáveis). Com base em tais resultados, não é possível afirmar, categoricamente, que há uma relação clara entre grau de definitude do objeto e grau de aceitabilidade das sentenças VOS do PE. Portanto, é plausível defendermos uma derivação via movimento-p do objeto para as sentenças VOS do PE.

\subsection{A estrutura entoacional associada às sentenças VOS do $\mathrm{PE}^{16}$}

Através da observação de dados empíricos, constata-se que a estrutura entoacional associada às sentenças VOS do PE apresenta propriedades especiais que as diferenciam prosodicamente das sentenças SVO neutras da mesma variedade de português. Atentemo-nos ao exemplo em (23) e às respectivas representação prosódica em (23’) e Figura 2 ilustrativa, extraídos do trabalho de Fernandes (2007a).

(23) Levaram as malas as governadoras.

(23') [((levaram)PWd] PPh[(as MAlas)PWd]PPh[(as governadoras)PWd]PPh]I

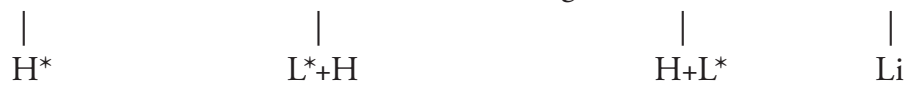

16 Para a descrição das características entoacionais das sentenças VOS do PE, valer-nos-emos dos resultados obtidos por Fernandes (2007a).

Fernandes-Svartman FR. Sentenças VOS em português europeu: movimento-p e estrutura entoacional 


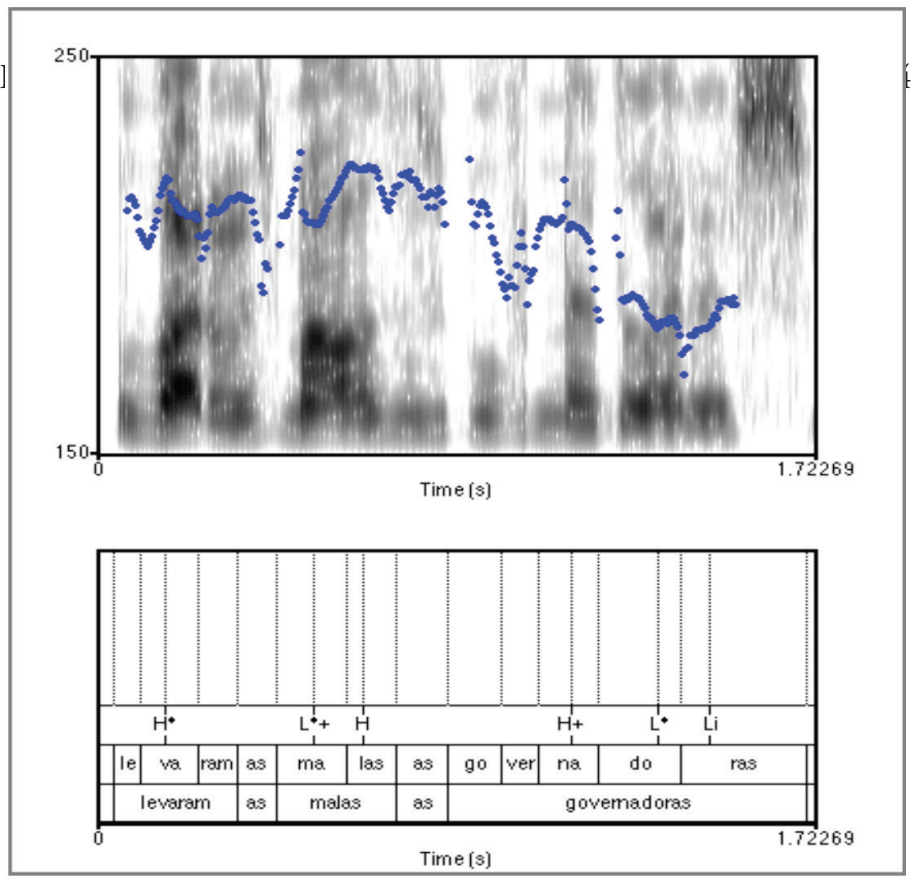

Figura 2. Contorno de $\mathrm{F}_{0}$ da sentença "Levaram as malas as governadoras", produzida em contexto de foco informacional no sujeito por um falante nativo de PE

Enquanto nas sentenças SVO neutras de PE, há eventos tonais associados apenas às palavras prosódicas (PWds) inicial e final do sintagma entoacional (I), nas sentenças VOS do PE, há acentos tonais associados às PWds-cabeça de cada sintagma fonológico $(\mathrm{PPh})$ de $\mathrm{I}$, como pode ser constatado pela observação da representação prosódica em (23’) e da Figura 2. Em outras palavras, as sentenças VOS de PE possuem características entoacionais que as diferenciam das sentenças SVO neutras de PE. Por outro lado, essa mesma propriedade entoacional descrita para as sentenças VOS do PE é também encontrada associada a outras estruturas sintáticas especiais dessa mesma variedade, como é o caso das sentenças com elementos deslocados analisadas por Frota (1994), das sentenças com advérbios em diferentes posiçóes e com diferentes escopos analisadas por Vigário, (1998), das sentenças na ordem advérbio-verbo-sujeito analisadas por Fernandes (2007a), ou ainda, como é o caso das sentenças pseudo-clivadas analisadas em Fernandes (2007a) e Fernandes-Svartman (2007b).

Além do fato de haver um acento tonal associado a cada PWd-cabeça dos PPhs do I no qual é mapeada a sentença VOS de PE, outra característica entoacional peculiar desse mesmo tipo de sentença é o fato de ser encontrado um acento tonal específico, $\mathrm{L}^{*}+\mathrm{H}$, associado à PWd-cabeça do PPh no qual o elemento movido da margem direita da sentença (conforme nossa análise, o objeto "as 
malas") é mapeado. É possível que essa característica entoacional codifique, por hipótese, o movimento prosódico (movimento-p) do objeto nas sentenças VOS do PE. Assim sendo, tal fato configurar-se-ia como uma evidência prosódica adicional em favor da análise da derivação das sentenças VOS do PE aqui proposta, via movimento-p do objeto.

Por outro lado, quanto ao sujeito das sentenças VOS de PE, embora ocupe uma posição distinta (SpecVP) da posição ocupada por ele nas sentenças SVO neutras (SpecIP) e seja focalizado informacionalmente, não foi encontrado nenhum acento tonal especial a ele associado, como, por exemplo, o acento tonal $\mathrm{H}^{*}+\mathrm{L}$, específico de foco prosódico em PE (Frota, 2000). Ao sujeito focalizado informacionalmente das sentenças VOS, foi encontrado associado apenas o acento tonal $\mathrm{H}_{+} \mathrm{L}^{*}$, típico de final de enunciado declarativo em PE (Frota, 2000).

\section{CONSIDERAÇÓES FINAIS}

Neste trabalho foram apresentados uma proposta de análise da estrutura sintática das sentenças VOS de PE e um estudo da estrutura entoacional associada a essas sentenças.

Quanto à análise da estrutura sintática das sentenças VOS de PE, foram trazidos mais argumentos, de cunho sintático e prosódico, em favor da análise encontrada em Fernandes (2007a) para a derivação das sentenças VOS de PE, via movimento-p do objeto.

Por sua vez, no que tange ao estudo da estrutura entoacional das sentenças VOS de PE, com base nos resultados de Fernandes (2007a), foi confirmada a hipótese inicial deste trabalho, na medida em que a estrutura entoacional associada às sentenças VOS de $\mathrm{PE}$ se revelou distinta da estrutura entoacional associada às sentenças SVO neutras da mesma variedade de português. Enquanto nas sentenças SVO neutras de PE foram encontrados eventos tonais associados apenas às palavras prosódicas inicial e final do I no qual a sentença é mapeada, nas sentenças VOS de PE, foram encontrados acentos tonais associados a cada palavra prosódica cabeça de sintagma fonológico de I, semelhantemente ao que é descrito para as estruturas entoacionais associadas a outras estruturas sintáticas especiais do PE, como as analisadas por Frota (1994), Vigário (1998), Fernandes (2007a) e Fernandes-Svartman (2007b).

Ademais, com relação ao sujeito nas sentenças VOS do PE, embora ocupe uma posição diferente (SpecVP) da ocupada por ele nas sentenças SVO neutras da mesma variedade (SpecIP) e seja focalizado informacionalmente, a ele, não se encontrou associada nenhuma informação prosódica especial (especificamente, entoacional), mas sim, ao elemento movido da margem direita da sentença, 
o objeto, conforme a análise apresentada neste trabalho. Associado à palavra prosódica cabeça do sintagma fonológico no qual é mapeado este elemento, foi encontrado um acento tonal específico, $\mathrm{L}^{*} \mathrm{H}$, que, por hipótese, codifica prosodicamente o movimento-p sofrido por ele. Isso posto, tal codificação prosódica consistiria em uma evidência prosódica adicional para a derivação das sentenças VOS de PE, através de movimento-p do objeto, conforme apresentado neste trabalho.

\section{REFERÊNCIAS}

Âmbar M. Para uma sintaxe da inversão sujeito-verbo em Português. Lisboa: Ediçôes Colibri; 1992.

Âmbar M. Aspects of the syntax of focus in Portuguese. In: Rebuschi G, Tuller L, editores. The grammar of focus. Amsterdam/Philadelphia: John Benjamins Publishing Company; 1999. p. 23-53.

Âmbar M, Pollock J-Y. Topique et commentaire dans quelques constructions à inversion du sujet en français et portugais. Universidade de Lisboa e UPR 9075, CNRS, Lyon; ms.

Barbosa P. Null subjects [tese]. Mass.: MIT; 1995.

Barbosa P. Clitics: a window into the null subject property. In: Costa J, organizador. Essays in Portuguese comparative syntax. New York: Oxford Press; 2000. p. 31-93.

Beckman M, Pierrehumbert J. Intonational structure in Japanese and English. Phonology Yearbook. 1986;3:255-309.

Belletti A. Generaralized verb movement: aspects of verb syntax. Turin: Rosenberg \& Sellier; 1990.

Belletti A. 1999. 'Inversion' as focalization and related questions. Catalan Working Papers in Linguistics. 1999;7:9-45.

Bok-Bennema R. Remnant VP movement in Spanish. Going Romance; 1998 December 11; Utrecht, Holland. 
Chomsky N. Minimalist inquiries: the framework. In: Martin R, Michaels D, Uriagereka J, editores. Step by step: essays on Minimalist Syntax in honor of Howard Lasnik. Cambridge, Mass.: MIT Press; 2000. p. 89-157.

Chomsky N. Derivation by phase. In: Kenstowicz M, editor. Ken Hale: A life in Language. Cambridge/Mass: MIT Press; 2001. p. 1-54.

Chomsky N. Beyond explanatory adequacy. In: Belletti A, editora. Structures and beyond: the cartography of syntactic structures, Vol. 3. Oxford: University Press; 2004. p. 104-132.

Chomsky N, Halle M. The sound pattern of English. New York: Harper and Row; 1968.

Costa J. Word order and constraint interaction. In: Baptista J, Barbosa P, organizadores. Seminários de Linguística. Algarve: Universidade do Algarve; 1996. p. 65-102.

Costa J. Word Order Variation. A constaint-based approach. Netherlands: Holland Academic Graphics; 1998.

Costa J. Spec, IP ou deslocado? Prós e contras das duas análises dos sujeitos pré-verbais. D.E.L.T.A. 2001;17(2):283-303.

Costa J. Subject positions and interfaces: the case of European Portuguese. Berlin/New York: Mouton de Gruyter; 2004.

Costa J, Galves C. External subjects in two varieties of Portuguese evidence for a non -unified analysis. In: Beyssade $\mathrm{C}$ et al, organizadores. Romance languages and linguistic theory 2000. Amsterdam/Philadelphia: John Benjamins Publishing Company, Vol. 232; 2002. p. 109-125.

Duarte I. A construção de topicalização na gramática do português [tese]. Lisboa: Universidade de Lisboa, Faculdade de Letras; 1987.

Duarte I. A topicalização do português europeu: uma análise comparativa. In: Duarte I, Leiria I, editores. Actas do Congresso Internacional sobre o Português. Lisboa: APL/ Colibri; 1996.

Duarte I, Matos G. Romance clitics and the Minimalist Program. In: Costa J, editor. Portuguese syntax: new comparative studies. Oxford: Oxford University Press; 2000. p. 116-142. 
Fernandes F. Peso fonológico e foco informacional no sujeito em português europeu. In: Oliveira F, Barbosa J, organizadores. XXI Encontro da Associação Portuguesa de Linguística - Textos seleccionados. Lisboa: Colibri Artes Gráficas, Vol. 1; 2006. p. 371-386.

Fernandes F. Ordem, focalização e preenchimento em português: sintaxe e prosódia [tese]. Campinas: Universidade Estadual de Campinas, Instituto de Estudos da Linguagem; 2007a.

Fernandes-Svartman, F. Entoação e domínios prosódicos em sentenças pseudo-clivadas do português europeu. Letras de Hoje. 2007b; 42 (3):69-88.

Figueiredo Silva C. A posição sujeito no português brasileiro: frases finitas e infinitivas. Campinas: Editora da Unicamp; 1996.

Frota S. Aspectos da prosódia do foco no português europeu. Letras de Hoje. 1994;29(4):77-99.

Frota S. On the prosody and intonation of focus in European Portuguese. In: MartínezGil F, Morales-Front A, editores. Issues in the Phonology and Morphology of the Major Iberian Languages. Washington, D.C.: Georgetown University Press; 1997. p. 359-392.

Frota S. Prosody and focus in European Portuguese: phonological phrasing and intonation. New York: Garland Publishing; 2000.

Frota S. Nuclear falls and rises in European Portuguese: a phonological analysis of declarative and question intonation. Probus. 2002a;14(1):113-146.

Frota S. Tonal association and target alignment in European Portuguese nuclear falls. In: Gussenhoven C, Warner N, editores. Laboratory Phonology 7. Berlin/New York: Mouton de Gruyter; 2002b. p. 387-418.

Frota S. The phonological status of initial peaks in European Portuguese. Catalan Journal of Linguistics. 2003;2:133-152.

Frota S, Vigário M. Aspectos de prosódia comparada: ritmo e entoação no PE e no PB. In: Castro RV, Barbosa P, editores. Actas do XV Encontro Nacional da Associação Portuguesa de Linguística, Vol. 1. Coimbra: APL; 2000. p. 533-555. 
Galves C. O enfraquecimento da concordância no português brasileiro. In: Roberts I, Kato M, organizadores. Português brasileiro, uma viagem diacrônica. Campinas: Editora da Unicamp; 1993.

Galves C. Ensaios sobre as gramáticas do português. Campinas: Editora da Unicamp; 2001.

Iatridou S. About Agr(P). Linguistic Inquiry. 1990;21(4):551-577.

Kato M. Strong and weak pronominals in the null subject parameter. Probus. 1999;11:1-37.

Kato M. The partial pro-drop nature and the restricted VS order in Brazilian Portuguese. In: Kato M, Negrão E, editores. Brazilian Portuguese and the null subject parameter. Madrid: Iberoamericana; 2000. p. 223-258.

Kayne R. Overt versus covert movement. Syntax. 1998;1:128-191.

Kayne R, Pollock J-Y. 1998. New thoughts on stylistic inversion. Workshop on Inversion in Romance; 1998; Amsterdan, Holland.

Ladd DR. Intonational Phonology. Cambridge: CUP; 1996.

Ladd DR. Intonational Phonology. 2nd ed. Cambridge: CUP; 2008.

Martins AM. Os clíticos na história do português [tese]. Lisboa: Universidade de Lisboa; 1994.

Pierrehumbert J. The phonology and phonetics of English intonation [tese]. Mass.: M.I.T; 1980.

Pierrehumbert J, Beckman M. Japanese tone structure. Cambridge, Mass.: M. I. T. Press; 1988.

Pollock J-Y. Verb movement, universal grammar and the structure of IP. Linguistic Inquiry. 1989;20(3):365-424. 
Tavares Silva C. A natureza de AGR e suas implicaçôes na ordem VS: um estudo comparativo entre o português brasileiro e o português europeu [tese]. Alagoas: Universidade Federal de Alagoas, Faculdade de Letras; 2004.

Vikner S. Scandinavian object shift and West Germanic scrambling. In: Corver M, Riemsdijk HV. Studies on scrambling: movement and non-movement approaches to free word order phenomena. Berlin/New York: Mouton de Gruyter; 1994. p. 487-515.

Vigário M. Aspectos da prosódia do português europeu: estruturas com advérbio de exclusão e negação frásica. Braga: CEHUM; 1998.

Vigário M. The Prosodic Word in European Portuguese. Berlin/New York: Mouton de Gruyter; 2003.

Zubizarreta ML. Prosody, Focus and Word Order. Cambridge/Mass: M. I. T. Press; 1998. 